DOI 10.37882/2223-2982.2021.01.33

\title{
ФЕНОМЕН СМЕШАННОЙ МЕТАФОРЫ: ТЕОРЕТИЧЕСКИЕ ПРЕДПОСЫЛКИ ИССЛЕДОВАНИЯ
}

\section{THE PHENOMENON OF MIXED METAPHOR: THEORETICAL BACKGROUND OF THE RESEARCH}

Summary: This article is devoted to the study of the main characteristics of metaphor throughout the development of science and mixed metaphor as a linguo-cognitive phenomenon. The evolution of the analysis of the essence of a metaphor is traced and its functions and concepts are revealed as the lines of its interpretation in order to determine the main theoretical premises for the study of mixed metaphor in the modern cognitive science.

Keywords: metaphor; mixed metaphor; malaphor; linguistic creativity; cognitive linguistics.

\author{
Таймур Мария Павловна \\ Преподаватель, Московский государственный \\ лингвистический университет \\ mariataymour@gmail.com
}

Аннотация: Данная статья посвящена исследованию основных характеристик метафоры на протяжении развития науки и смешанной метафоры как лингвокогнитивного феномена. Прослеживается эволюция анализа сущности метафоры и выявляются ее функции и концепции как линии ее трактовки для определения основных теоретических предпосылок исследования смешанной метафоры в современной когнитивной науке.

Ключевые слова: метафора; смешанная метафора; малафора; лингвокреативность; когнитивная лингвистика.

М. Блэка [Black 1955]. Последний поставил несколько важных вопросов относительно проблемы метафоры:

- как можно обнаружить метафору;

- есть ли для этого какие-либо критерии;

- почему человек использует метафоры.

Блэком было введено понятие фокуса метафоры (слова, используемого метафорически) и понятие фрейма (других слов в выражении, используемых буквально), а также несколько принципов рассмотрения метафоры:

- рассмотрение метафоры с точки зрения замещения;

- рассмотрение метафоры с точки зрения сравнения;

- рассмотрение метафоры с точки зрения взаимодействия;

- рассмотрение метафоры с точки зрения системы повседневных ассоциаций.

Для описания последнего принципа ученый предложил термины «вспомогательный субъект» как описываемое явление и «основной субъект» как непосредственно описание, позже названные «целевой домен» и «доменисточник» соответственно [Lakoff, Johnson 1980].

На основании анализа сущности метафоры как стилистического приема в результате ее философско-лингвистического осмысления можно выделить следующие основные концепции как линии ее трактовки: субституциональная (метафора - это замена одного слова на другое); сравнительная (буквальное значение языковых единиц в метафоре трансформируется); интеракционистская (перефразирование метафоры ведет к потере 
ее смысла). При рассмотрении смешанной метафоры как лингвокогнитивного феномена можно прийти к выводу, что в то время, как первые две концепции (субституциональная и сравнительная) сохраняют свою актуальность, последняя (интеракционистская) часто нарушается. Это происходит, в особенности, в ядре категории т.н. малафоре как намеренном (либо случайном) соединении в единой фразе двух и более устойчивых выражений (идиом, афоризмов), напр., It's not rocket science, Не плюй в колодец - вылетит, не поймаешь, либо замене одного или нескольких слов в стандартной метафоре, напр. Nothing to shake home about, Долг платежом страшен. Причем, данное утверждение относится как к мономодальным (вербальным), так и мультимодальным смешанным метафорам [см. подробнее Голубкова, Таймур 2020; Таймур 2020 (b); Forceville 2016; Perez-Sobrino 2016].

Основными функциями метафоры могут считаться онтологическия, гносеологическая, номинативная, методологическая, мировоззренческая (или этико-эмоциональная) и эстетическая, однако на разных этапах развития философии и языкознания главенствующую роль играли различные ее функции, анализ которых необходим для определения функций смешанной метафоры в современной коммуникации. В греческой философии в основном проявляются номинативная и онтологическая функции метафоры, где она формирует новые философские термины. В сциентистски-ориентированной западноевропейской лингвистике и философии 16-17 вв. особую роль играет объяснительная функция метафоры в процессе донесения до индивида новых научных идей [Бэкон 1978]. Метафора, в которую вкладывается новый смысл при ее переосмыслении, используется для критического анализа. Основные функции метафоры (объяснительная, инструментальная, этико-эмоциональная) соединяются, конвертируя метафору в своего рода ядро аналогии, способ ее вы- ражения и фиксации. В неклассический период работы Ницше, выступающего за реформу языка как способа кардинального изменения смыслового наполнения предыдущей философии и культуры, демонстрируют эмоционально-экспрессивную функцию метафоры как основную - в новом языке она начинает играть роль эмоционального воздействия на читателя, разрушая устоявшиеся стереотипы [Ницше 1990].

На сегодняшний день с помощью инструментов когнитивной лингвистики может быть выявлена когнитивная природа метафоры на протяжении всего развития науки. Со времен античности многообразие человеческого знания постоянно культивируется, а многофункциональность метафор прекрасно соответствует данной особенности знания индивида. В современной науке интерес к метафоре не только не снижается, но и продолжает расти, захватывая не только разные школы философии и лингвистическую философию, но и такие гуманитарные отрасли науки, как психологию, семиотику, логику, риторику и, в особенности, когнитивную лингвистику, становясь предметом ее пристального изучения [см. подробнее Голубкова, Таймур 2019; Таймур 2020 (а); Kimmel 2009; Müller 2016]. Сегодня основными функциями как метафоры, так и смешанной метафоры, помимо вышеупомянутых, можно назвать такие когнитивные функции, как облечение новых мыслей индивида в определенную форму для выражения новых способов и типов мышления (т.е. когнитивный процесс концептуализации человеческого опыта), компрессия информации в условиях изменения условий жизни. Также на первый план выходит понятие лингвистической креативности в процессе коммуникации. Это и объясняет интерес когнитивной лингвистики к смешанной метафоре и ее подвидам как яркому проявлению творческого потенциала мышления и языка, лингвокреативной деятельности индивида.

\section{ЛИТЕРАТУРА}

1. Бэкон Ф. Сочинения в 2-х томах. М.: Мысль, 1978. 575 с.

2. Голубкова Е.Е., Таймур М.П. Факторы преодоления когнитивного диссонанса в смешанных метафорах (на материале английского языка) // Когнитивные исследования языка. 2019. №36. С. 147-154.

3. Голубкова Е.Е., Таймур М.П. Вербально-графическая метафора: рецепты успешного приготовления // Когнитивные исследования языка. 2020. №41. С. 386-391.

4. Ницше Ф. Сочинения. В 2-х т. Перевод с немецкого Я. Бермана. М.: Издательство «Мысль», 1990. 833 с.

5. Таймур М.П. Классификация смешанных метафор: когнитивные предпосылки // Современная наука: актуальные проблемы теории и практики. Гуманитарные науки. 2020. №2. С. 176-178. (а)

6. Таймур М.П. Смешанная метафора и малафора в когнитивной анти-меметике на материале английского языка // Филологические науки. Вопросы теории и практики. 2020. Т.13. №5. С. 236-240. (b)

7. Black M. Models and Metaphors. USA: Ithaca New York, Cornell University Press, 1962. 276 p.

8. Forceville C. Mixing in pictorial and multimodal metaphors? // Gibbs R. W. Jr. (ed.), Mixing Metaphors. Amsterdam: John Benjamins, 2016. P. 223-239.

9. Kimmel M. Why We Mix Metaphors (and Mix Them Well) // Journal of Pragmatics, 42. University of Vienna, 2009. P. 97-115.

10. Lakoff G., Johnson M. Metaphors We Live By. USA: University of Chicago Press, 1980. 252 p.

11. Müller C. Why mixed metaphors make sense // Mixing Metaphor. Gibbs R.W. Jr. (ed.). Amsterdam / Philadelphia: John Benjamins Publishing Company, Chapter 3, 
2016. P. 31-56.

12. Perez-Sobrino P. Shockvertising: conceptual interaction patterns as constrains on advertising creativity. // Círculo de Lingüística Aplicada a la Comunicación. 2016. № 62, 2016. P. 257-290.

13. Richards I. A. The philosophy of rhetoric. UK: Oxford University Press, 1936. $106 \mathrm{p}$.

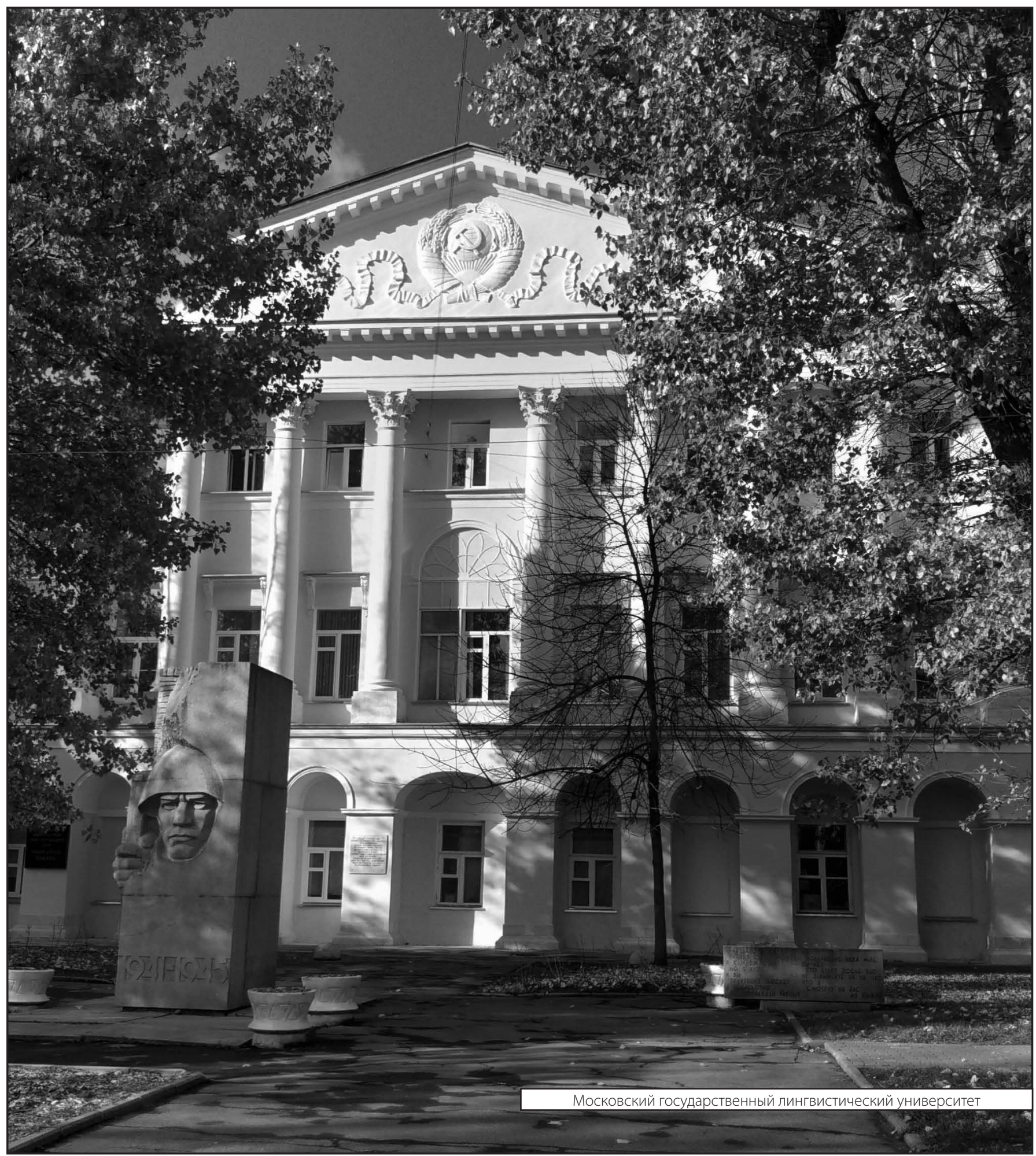

